\title{
Amphiregulin/epiregulin mRNA Expression and Primary Tumor Location in Colorectal Cancer
}

\author{
HIDEKAZU KURAMOCHI ${ }^{1}$, GO NAKAJIMA ${ }^{2}$, KAZUHIKO HAYASHI ${ }^{2}$, \\ TATSUO ARAIDA ${ }^{3}$ and MASAKAZU YAMAMOTO ${ }^{4}$ \\ ${ }^{1}$ Department of Chemotherapy, Yachiyo Medical Center, Tokyo Women's Medical University, Chiba, Japan; \\ ${ }^{2}$ Department of Chemotherapy and Palliative Care, Tokyo Women's Medical University, Tokyo, Japan; \\ ${ }^{3}$ Department of Surgery, Yachiyo Medical Center, Tokyo Women's Medical University, Chiba, Japan; \\ ${ }^{4}$ Department of Gastrointestinal Surgery, Tokyo Women's Medical University, Tokyo, Japan
}

\begin{abstract}
Background/Aim: Amphiregulin (AREG) and epiregulin (EREG) $m R N A$ expression levels are predictors of response to anti-EGFR antibody therapy. Left-sided colon cancer is more sensitive to anti-EGFR antibodies than rightsided, although the mechanism is unclear. The aim of this study was to determine the relationship between AREG, EREG $m R N A$ expression levels and tumor location as well as the efficacy of anti-EGFR antibody agents. Materials and Methods: Real-time PCR was used to assess AREG and EREG mRNA expression in metastatic colorectal cancer (CRC) samples from 153 patients. Results: Among KRAS ${ }^{\text {wt }}$ samples, high AREG expression (AREG ${ }^{\text {High }}$ ) was significantly more common in left-sided tumors than in rightsided. Among patients who received anti-EGFR antibody, response rates were significantly higher in $A R E G^{\text {High }}$ than in $A R E G^{L o w}$. In the left-sided tumor group, overall survival was significantly longer in patients with high EREG levels than with low levels, whereas the right-sided tumor group showed no survival difference between them. Conclusion: AREG and EREG $M R N A$ expression levels in left-sided CRC were higher than in right-sided tumors. This may help explain why left-sided CRC is more responsive to anti-EGFR antibodies.
\end{abstract}

Amphiregulin (AREG) and epiregulin (EREG) belong to the epidermal growth factor (EGF) family, and act as mitogenic stimulators through binding to EGFRs (1). Recently, patients with high $A R E G$ and $E R E G$ expression in tumor cells were

Correspondence to: Hidekazu Kuramochi, Tokyo Women's Medical University, Yachiyo Medical Center, Department of Surgery, 47796 Owadashinden, Yachiyoshi, Chiba 276-8524, Japan. Tel: +81 474506000, Fax: +81 474587047, e-mail: kuramochi.hidekazu@ twmu.ac.jp

Key Words: Amphiregulin (AREG), epiregulin (EREG), colorectal cancer, tumor location, anti-EGFR antibody. reported to respond better to anti-EGFR antibody agents (cetuximab $[\mathrm{CTX}] /$ panitumumab $[\mathrm{Pmab}] ; \mathrm{C} / \mathrm{P}$ ) and survive longer than those with low expression among patients with unresectable/metastatic $R A S$-wild-type colorectal cancer (CRC) (2-13). Thus, AREG and EREG are potential alternative biomarkers for anti-EGFR antibodies.

Tumor location is also associated with prognosis in CRC. Patients with left-sided tumors show a better survival than those with right-sided tumors, regardless of therapy (14). Tumor location is also associated with response to $\mathrm{C} / \mathrm{P}$. In the CALGB 80405 study, among patients with $R A S / B R A F$ wild-type tumors, in the subset with left-sided CRC, those treated with CTX had 2 months' gain in overall survival (OS) compared to those treated with bevacizumab, whereas in the right-sided subset, patients treated with CTX showed 16 months' loss of OS compared to those treated with bevacizumab (15). Although many studies support the consensus that anti-EGFR antibody agents are more effective on left-sided tumors than right-sided ones, (16-19) the reason for this difference of efficacy is unclear. Lee et al. reported that $E R E G$ and $A R E G$ expression was inversely correlated with both methylation and right-sidedness in primary tumors, which suggests that these differences are related to the association between tumor location and C/P efficacy (20).

In this study, we compared mRNA expression levels of $A R E G$ and EREG in left-sided and right-sided tumors in 153 CRC patients, and evaluated the association between $A R E G$ and $E R E G$ expression and tumor location with efficacy of $\mathrm{C} / \mathrm{P}$ in 49 patients.

\section{Materials and Methods}

Patients and samples. We analyzed data and specimens from 153 patients with metastatic or relapsed CRC who had undergone resection of primary colorectal adenocarcinomas between 2003 and 2013 in the Department of Gastroenterology, Tokyo Women's Medical University, Tokyo, Japan $(n=136)$, or Tokyo Women's Medical University, Yachiyo Medical Center, Chiba, Japan ( $n=17)$. 
The patients' relevant characteristics are shown in Table I. Of the 153 samples, 100 were $K R A S$ exon 2 (codon 12,13) wild-type $\left(K R A S^{w t}\right)$ and 53 were mutant type $\left(K R A S^{M u t}\right)$. Of these 153 patients, 49 patients $\left(K R A S^{w t}: \mathrm{n}=37 ; K_{R A S^{M u t}}\right.$ : $\mathrm{n}=10$; unknown: $\mathrm{n}=2)$ had received anti-EGFR antibodies $(\mathrm{C} / \mathrm{P})$.

Primary specimens were classified as having right-sided CRC if they were located in the cecum, ascending colon, hepatic flexure, or transverse colon, and left-sided CRC if the tumor site was within the splenic flexure, descending colon, sigmoid colon, or rectum.

This study was approved by the Ethics Committee of Tokyo Women's Medical University and performed in accordance with the Declaration of Helsinki. All patients were Japanese, and all had given their written informed consent according to the institutional regulations.

Microdissection. Formalin-fixed, paraffin-embedded tumor specimens were cut into $10-\mu \mathrm{m}$-thick serial sections. For pathological diagnosis, one slide for each specimen was stained with hematoxylin and eosin and evaluated by a pathologist. Manual microdissection using a scalpel was performed if histology was homogeneous and contained $>90 \%$ cancer cells. For all other samples, laser-capture microdissection (P.A.L.M. Microlaser Technologies AG, Munich, Germany) was performed to ensure that only tumor cells were dissected.

RNA isolation and cDNA synthesis. Isolation of RNA from formalin-fixed paraffin-embedded (FFPE) specimens was performed using a RNeasy FFPE Kit (Qiagen, Tokyo, Japan) according to the manufacturer's instructions. We converted cDNA from the total RNA yielded, using a High Capacity cDNA Reverse Transcription Kit (Applied Biosystems, Tokyo, Japan).

Reverse transcription-PCR. cDNA was pre-amplified using a TaqMan PreAmp Master Mix Kit (Applied Biosystems) according to the manufacturer's instructions. mRNA expression of $A R E G$, EREG, and a single internal reference gene (beta-2-macrogloblin) was measured by a fluorescence-based real-time polymerase chain reaction (PCR) detection method. Primers and probes were provided from TaqMan Gene Expression Assays (Applied Biosystems). The PCR Primer ID were AREG: Hs00950669_m1, EREG: Hs00914312_m1, and beta 2-microglobulin: Hs99999907_m1. The PCR methodology has been described previously (21). The $2^{-\Delta \Delta C T}$ number was used for relative mRNA quantification. The samples from Tokyo Women's Medical University Hospital were measured using StepOne real-time PCR system (Applied Biosystems), and the samples from Yachiyo Medical Center were measured using Illumina ECO Real-time PCR system (Illumina, San Diego, CA, USA). Because PCR machines differed between the two institutes, median values of $A R E G$ and $E R E G$ expression in each institute were used as cut-off values, to divide high and low expression.

Screening for KRAS mutation. DNA was extracted from the FFPE specimens using a Qiamp DNA FFPE Tissue Kit (Qiagen) according to the manufacturer's instructions. KRAS exon-2 mutations were detected by direct-sequencing, as previously described (22).

Statistical analysis. Frequencies of high and low gene expression were compared between left- and right-sided tumors using Fisher's exact test. Response rates and carcinoembryonic antigen (CEA) changing rates were compared between high- and low-gene
Table I. Demographic and clinical parameters of 153 patients with metastatic colorectal cancer.

\begin{tabular}{lcr}
\hline Characteristics & Frequency & $\%$ \\
\hline Age & & \\
Mean (range) & $64(32-91)$ & \\
Gender & & \\
Male & 89 & $58.2 \%$ \\
Female & 64 & $41.8 \%$ \\
Anatomical site & & \\
Cecum & 13 & $8.5 \%$ \\
Ascending & 31 & $20.3 \%$ \\
Transverse & 9 & $5.9 \%$ \\
Descending & 7 & $4.6 \%$ \\
Sigmoid & 54 & $35.3 \%$ \\
Rectum & 39 & $25.5 \%$ \\
KRAS exon 2 mutational status & & \\
Wild-type & 100 & $65.4 \%$ \\
Mutant & 53 & $34.6 \%$ \\
Institution & & \\
Tokyo Women's Medical Univ. & 136 & $88.9 \%$ \\
Yachiyo Medical Center & 17 & $11.1 \%$ \\
Received anti-EGFR therapy & & \\
$\quad$ Received & 49 & $68.0 \%$ \\
Not received & 104 & \\
\hline
\end{tabular}

Table II. Demographic and clinical parameters of 37 patients with $K R A S$ wild-type metastatic colorectal cancer treated with anti-EGFR therapy.

\begin{tabular}{|c|c|c|}
\hline Characteristics & Frequency & $\%$ \\
\hline \multicolumn{3}{|l|}{ Age } \\
\hline Mean (range) & $67(48-78)$ & \\
\hline \multicolumn{3}{|l|}{ Gender } \\
\hline Male & 21 & $56.8 \%$ \\
\hline Female & 16 & $43.2 \%$ \\
\hline \multicolumn{3}{|l|}{ Anatomical site } \\
\hline Cecum & 3 & $8.1 \%$ \\
\hline Ascending & 6 & $16.2 \%$ \\
\hline Transverse & 2 & $5.4 \%$ \\
\hline Descending & 2 & $5.4 \%$ \\
\hline Sigmoid & 12 & $32.4 \%$ \\
\hline Rectum & 12 & $32.4 \%$ \\
\hline \multicolumn{3}{|l|}{ Treatment line } \\
\hline 1st line & 3 & $8.1 \%$ \\
\hline 2nd line & 13 & $35.1 \%$ \\
\hline 3rd line & 21 & $56.8 \%$ \\
\hline \multicolumn{3}{|l|}{ Regimen } \\
\hline Cmab alone & 2 & $5.4 \%$ \\
\hline $\mathrm{Cmab}+\mathrm{CPT}-11$ & 14 & $37.8 \%$ \\
\hline $\mathrm{Cmab}+\mathrm{FOLFOX}$ & 4 & $10.8 \%$ \\
\hline Cmab + FOLFIRI & 3 & $8.1 \%$ \\
\hline Pmab alone & 4 & $10.8 \%$ \\
\hline Pmab + CPT-11 & 2 & $5.4 \%$ \\
\hline Pmab + FOLFIRI & 8 & $21.6 \%$ \\
\hline
\end{tabular}

Cmab: Cetuximab; CPT-11: irinotecan; Pmab: panitumumab. 


\section{KRAS wild-type $(n=100)$}

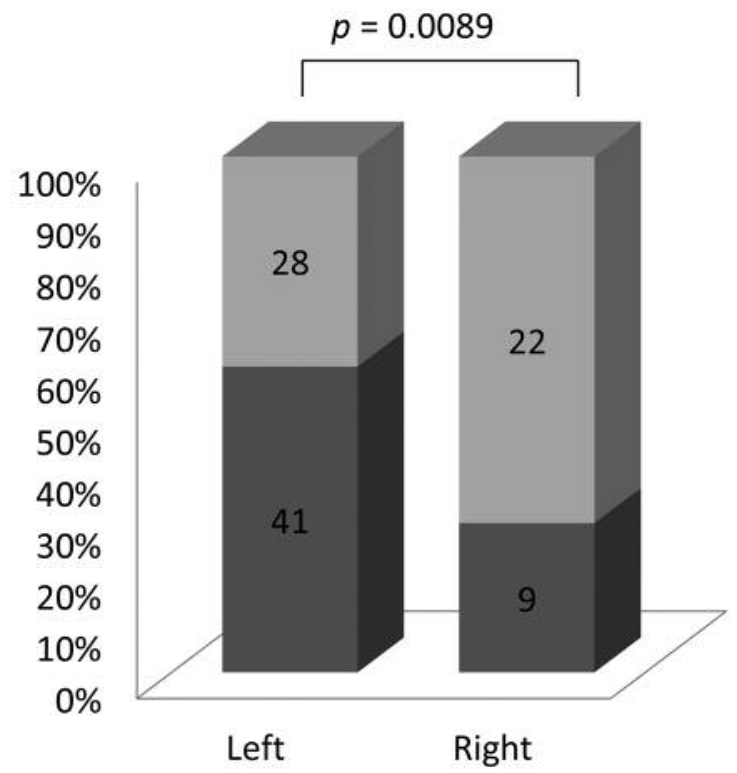

AREG high group $\quad$ AREG low group
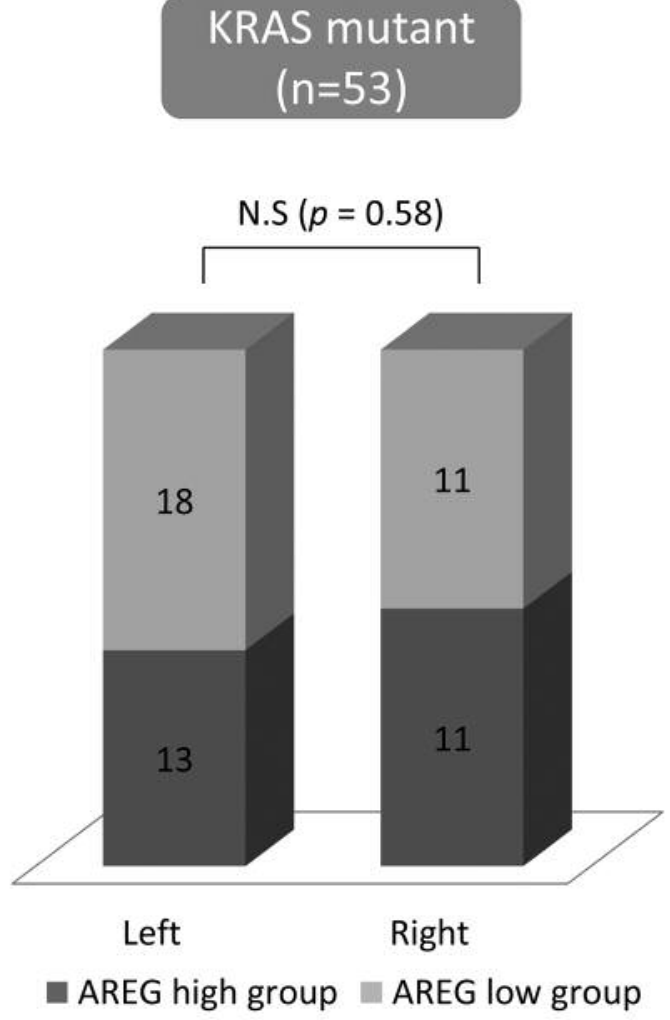

Figure 1. Percentages of AREGHigh patients by tumor side among KRAS wild-type and KRAS-mutant samples. Among KRAS wild-type patients, the percentage of AREGHigh patients was significantly higher in the left-sided subset than in the right-sided subset.

expression groups using the Wilcoxon signed-rank test. The Kaplan-Meier method was used to construct survival curves and the log-rank test for statistical analysis. The Cox proportional hazard regression model was used in multivariate analysis.

OS was defined as the time from the first administration of antiEGFR antibodies to death from any cause. CEA changing rate was defined as minimum serum CEA levels minus baseline CEA levels, divided by baseline CEA levels. Statistical analyses were performed using JMP 11 (SAS Institute, Cary, NC, USA). $p$-Value $<0.05$ was considered significant. All values are two-sided.

\section{Results}

AREG/EREG mRNA expression and tumor location. In the cohort as a whole, AREG/EREG mRNA expression levels did not significantly differ between left and right CRC. However, among $K R A S^{w t}$ samples $(\mathrm{n}=100), A R E G^{\text {High }}$ expression was significantly more common in left-sided CRC (high: $\mathrm{n}=41$, low: $n=28$ ) than in right-sided CRC (high: $n=9$, low: $n=22$; $p=0.0089$; Figure 1). Similar results were observed with EREG expression, although not significantly so (left-high: $\mathrm{n}=39$, low: $\mathrm{n}=30$; right-high: $\mathrm{n}=11$, low: $\mathrm{n}=20 ; p=0.08$ ). However, among KRAS $S^{M u t}$ patients (n=53), no association was observed in AREG or EREG mRNA expression levels between left- and right-sided tumors ( $A R E G$ : left-high: $\mathrm{n}=13$, low: $\mathrm{n}=18$; right-high: $\mathrm{n}=11$, low: $\mathrm{n}=11 ; p=0.58$. EREG: left-high: $\mathrm{n}=12$, low: $\mathrm{n}=19$; right-high: $\mathrm{n}=8$, low: $\mathrm{n}=14 ; p=1.00$ ).

AREG/EREG mRNA levels and response to anti-EGFR antibodies. Of the 153 patients, 49 received anti-EGFR antibodies (CTX/Pmab). As KRAS testing was only approved in Japan in 2010, 10 patients who were treated before approval had $K R A S^{M u t}$ tumors and two patients had unknown KRAS status; the other 37 patients had KRASwt tumors (Table II). Twenty-three patients received CTX-containing regimens, and 14 were administered Pmab regimens, mostly as 2nd- or 3rd-line treatments.

Response rates (RRs) for $K R A S^{w t}$ tumors were: $32.4 \%$ (12/37), KRAS ${ }^{M u t}$ tumors: 0\% (0/10). In the KRAS ${ }^{w t}$ group $(\mathrm{n}=37)$, RRs significantly differed between the $A R E G^{H i g h}$ group $(47.6 \%, 10 / 21)$, and the $A R E G^{\text {Low }}$ group (12.5\%, 2/16; $p=0.035)$, where the median value from each testing institution was used as the cut-off. RRs by EREG expression showed a similar trend (EREG ${ }^{H i g h}: 40.9 \%, E R E G^{\text {Low }}$ group: $20 \%)$, but was not significant $(p=0.28)$. 

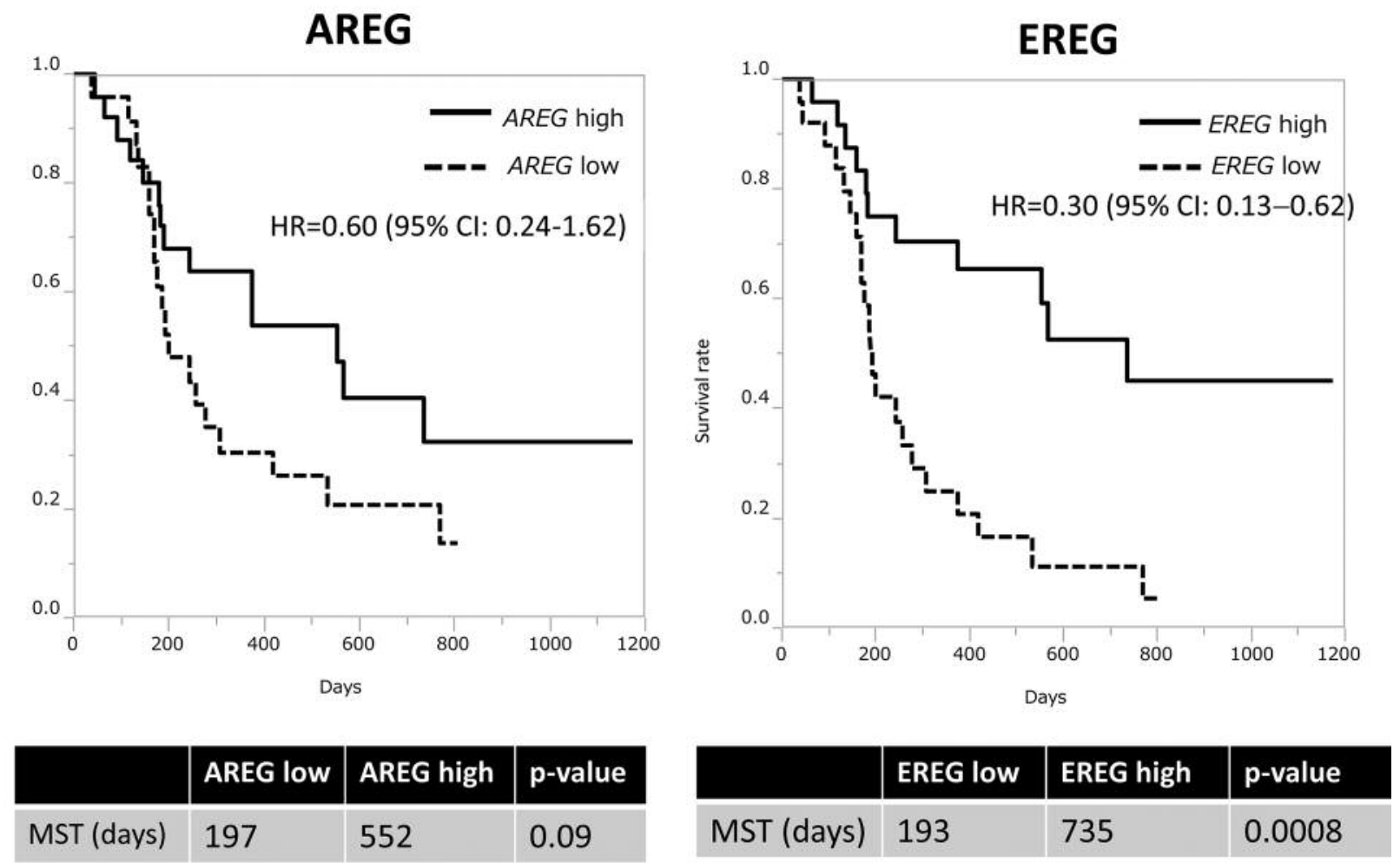

Figure 2. Overall survival (OS) in patients by AREG expression and EREG expression in patients who received anti-EGFR therapy. EREG expression levels clearly separated the patients with good and poor prognosis.

CEA changing rate was defined as ([minimum serum CEA] - [baseline CEA])/(baseline CEA). Median CEA changing rate in the $A R E G^{\text {High }}$ group $(-0.63)$ was significantly lower than in the $A R E G^{\text {Low }}$ group $(-0.13$; $p=0.027)$; and significantly lower in the $E R E G^{\text {High }}$ group $(-0.22)$ than in the $E R E G^{\text {Low }}$ group $(0.035 ; p=0.0038)$.

AREG and EREG mRNA levels and OS in C/P-treated patients. For all $49 \mathrm{C} / \mathrm{P}$-treated patients, median survival time (MST) was significantly longer in the $E R E G^{H i g h}$ group (735 days) than in the $E R E G^{\text {Low }}$ group (193 days, $p=0.0008$; hazard ratio $[\mathrm{HR}]=0.30$; $95 \%$ confidence interval $[\mathrm{CI}]=0.13-$ 0.62 ; Figure 2). This difference was even more pronounced in the $K R A S^{w t}$ group (n=37; MST: not reached vs. 169 days, $p=0.0035, \mathrm{HR}=0.29 ; 95 \% \mathrm{CI}=0.12-0.70)$.

$A R E G$ showed a similar trend for MST, but was not significant (all patients: $A R E G^{\text {High }}: 552$ days, $A R E G^{\text {Low }}: 197$ days, $p=0.09$, HR $=0.60,95 \% \mathrm{CI}=0.24-1.62$; Figure 2; KRAS ${ }^{w t}:$ AREG ${ }^{\text {High }}: 735, A R E G^{\text {Low }}: 193$ days, $p=0.17$, $\mathrm{HR}=0.56,95 \% \mathrm{CI}=0.23-1.32$ ).

Figure 3 shows a Kaplan-Meier curve for OS that combines $K R A S$ and EREG status. The $K R A^{S w t} / E R E G^{H i g h}$ group had the most favorable outcome (MST: not reached). Interestingly, MST in the subgroup of $E R E G^{L o w} / K R A S^{w t}$ patients who were treated with $\mathrm{C} / \mathrm{P}$ (169 days) was fairly similar to that of the
$K R A S^{M u t}$ group (226 days; Figure 3), which implies that the $E R E G^{\text {Low }}$ patients derived no benefit from $\mathrm{C} / \mathrm{P}$.

$C / P$ response by tumor location and AREG/EREG mRNA levels. We considered tumor location in $K R A S^{w t}$ tumors treated with anti-EGFR antibodies $(\mathrm{n}=37)$. The proportion of $A R E G^{\text {High }}$ tumors was significantly higher in left-sided CRC (73\%) than right-sided CRC $(18 \%, p=0.003)$. EREG showed a similar trend, but was not significant (left: 69\%, right: $36 \%, p=0.06$ ).

Among patients with left-sided CRC, RRs to $\mathrm{C} / \mathrm{P}$ in the $A R E G^{H i g h}$ group $(\mathrm{n}=19)$ were $47.4 \%$, and in the $A R E G^{\text {Low }}$ group $(\mathrm{n}=7) 28.6 \%$. Among those with right-sided tumors, the $A R E G^{\text {High }}$ group $(\mathrm{n}=2)$ included one responding patient $(50 \%)$, whereas no patients in the $A R E G^{\text {Low }}$ group ( $\mathrm{n}=9$ ) showed any response at all (0\%).

Tumor location and $O S$ in patients treated with $C / P$. In the $K R A S^{w t}$ group, among patients treated with $\mathrm{C} / \mathrm{P}(\mathrm{n}=37)$, MST was longer in the left-sided group (735 days) than in the right-sided group (169 days), but was not significant $(p=0.13)$. In the left-sided CRC $(\mathrm{n}=26)$, MST was significantly longer in the $E R E G^{\text {High }}$ group (MST: not reached) than in the $E R E G^{L o w}$ group (199 days; $p=0.018$; Figure 4). The $E R E G^{H i g h} /$ left-sided group had the most 


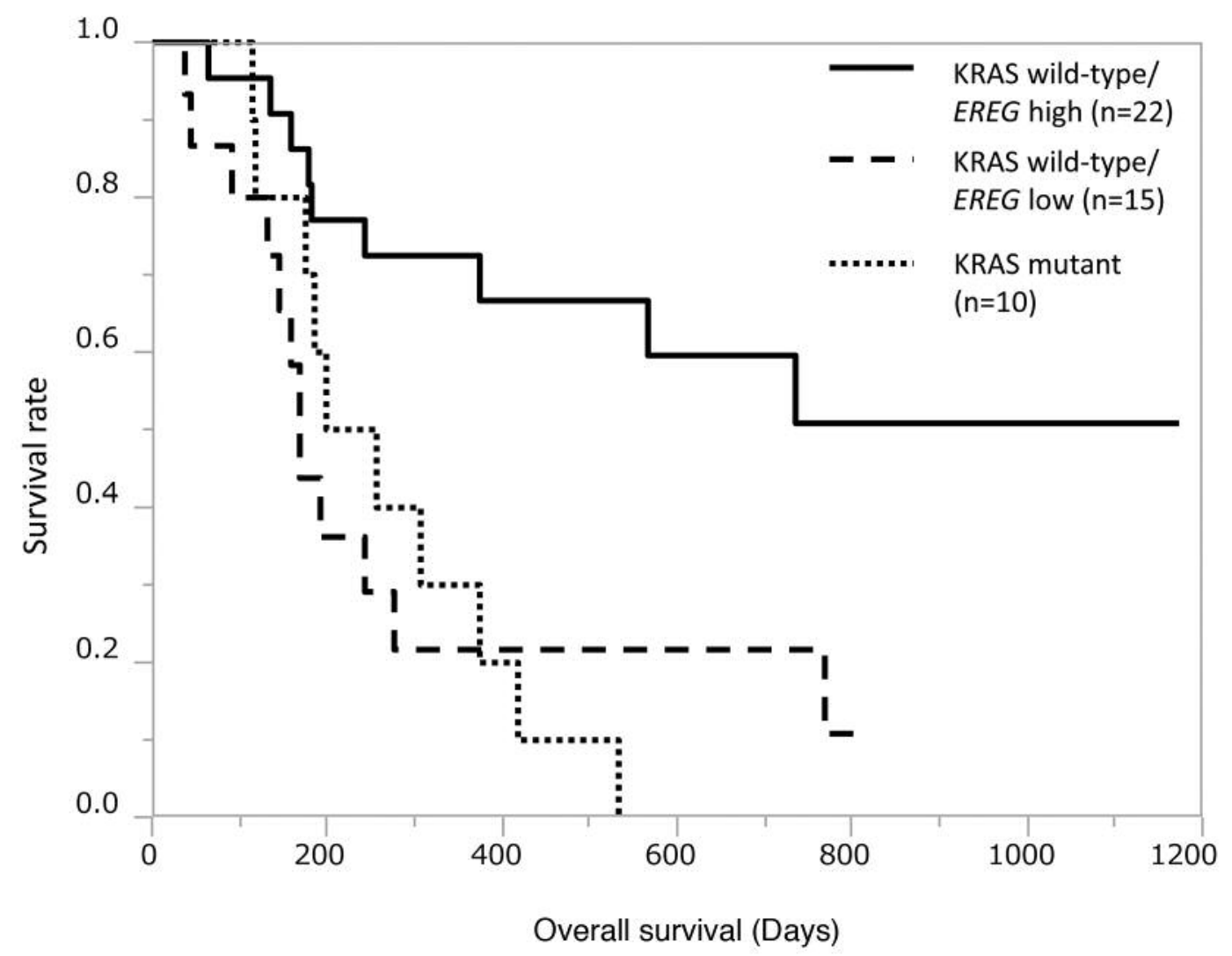

Figure 3. Overall survival (OS) by KRAS status and EREG expression in patients who received anti-EGFR therapy. The KRAS-wild-type/EREGHigh group had the most favorable outcome, whereas OS in the KRAS wild-type/EREG ${ }^{\text {Low }}$ group was similar to the KRAS-mutant group.

favorable outcome, whereas OS in $E R E G^{L o w}$ group, even with left-sided CRC, was similar to those with right-sided CRC. In multivariate analysis, only EREG expression was an independent prognostic indicator $(p=0.0088)$, whereas $A R E G$ expression $(p=0.41)$, tumor sidedness $(p=0.52)$, age (cut-off: 65 years; $p=0.98)$, sex $(p=0.18)$, and use of $\mathrm{C} / \mathrm{P}$ $(p=0.93)$ were not significantly relevant.

\section{Discussion}

Many recent studies support the association of tumor sidedness with response to C/P by metastatic CRC (16-19). Arnold et al. reported that OS and RR of patients who received anti-EGFR antibodies were significantly higher than those who did not receive anti-EGFR antibodies among patients with left-sided primary tumors, whereas no benefit from $\mathrm{C} / \mathrm{P}$ was observed in patients with right-sided tumors by meta-analysis of six clinical trials (16). However, the mechanism of this phenomenon is unclear.

In the present study, our data showed that high $A R E G$ mRNA expression is significantly more common in left- sided tumors than right-sided tumors. Lee et al. reported that $A R E G / E R E G$ expression was highly inversely correlated with the methylation of loci within the AREG/EREG promoters, and was inversely correlated with right-sided tumors and $\mathrm{CpG}$ island methylator phenotype (CIMP) status (20). They also reported that high CIMP status is associated with inferior progression-free survival (PFS) after $\mathrm{C} / \mathrm{P}$ treatment (20), although they did not directly evaluate AREG/EREG expression and PFS. Our data are compatible with their report, and directly show the association between tumor location, AREG/EREG expression, and prognosis of patients who received $\mathrm{C} / \mathrm{P}$, which implies that these factors are connected to the underlying mechanism of why $\mathrm{C} / \mathrm{P}$ is more effective in left-sided primary tumors than in rightsided tumors. Although our study cohort was relatively small, one patient in the $A R E G^{H i g h} /$ right-sided tumor group responded to $\mathrm{C} / \mathrm{P}$, although there were no responders in the $A R E G^{L o w} /$ right-sided tumor group. Even among patients with left-sided tumors, OS of the EREG ${ }^{\text {Low }}$ subgroup was similar to that in the right-sided tumor group. As variations in response to $\mathrm{C} / \mathrm{P}$ reflect differences in molecular profiles 


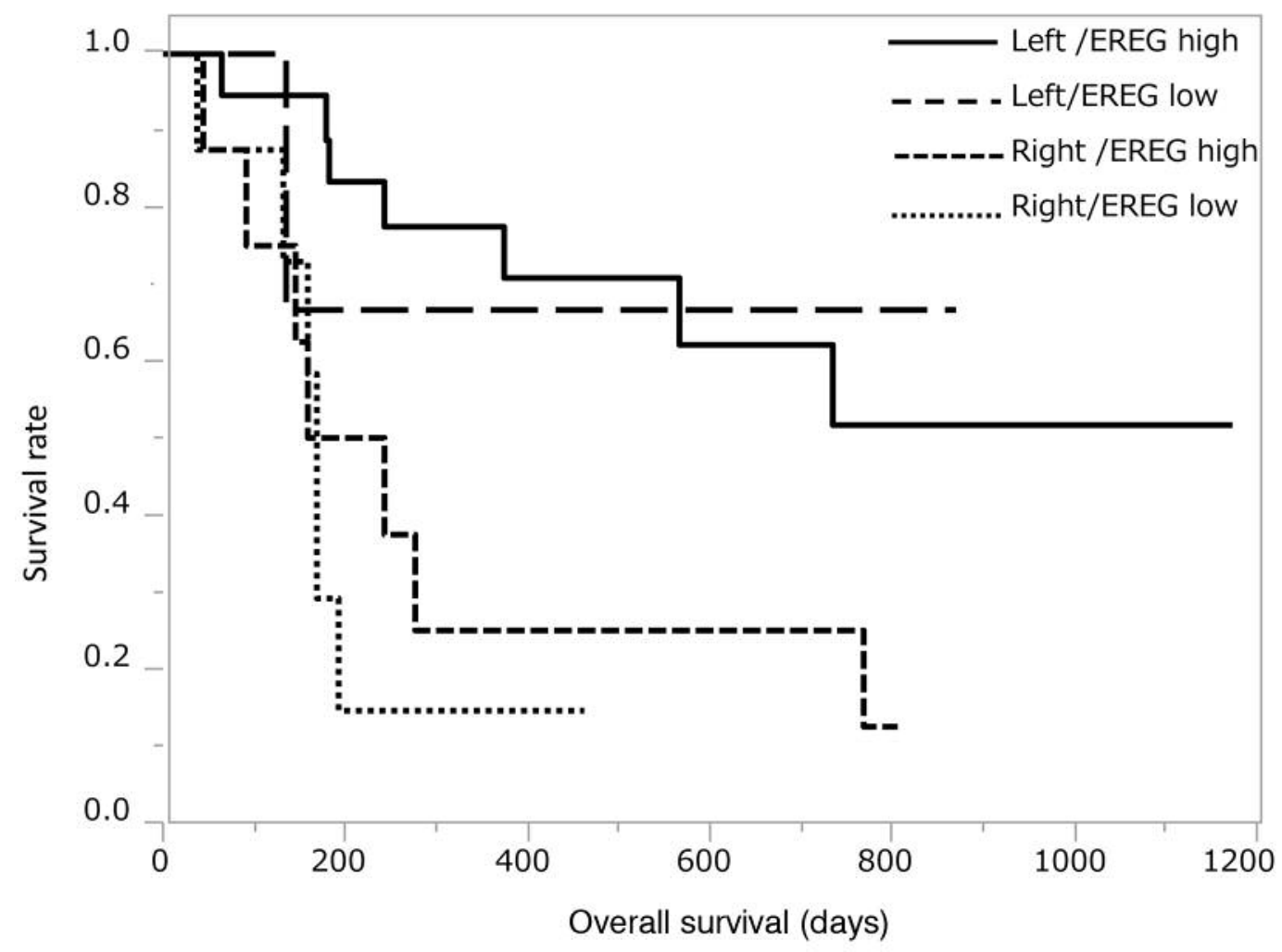

Figure 4. Overall survival (OS) by EREG expression and tumor sidedness among patients who received anti-EGFR therapy. The EREGHigh/leftsided group had the most favorable outcome, whereas among the right-sided group, EREG ${ }^{\text {Low }}$ and EREGHigh patients had similar outcomes.

such as $A R E G / E R E G$ expression, tumor location may be just a surrogate marker of these differences.

High $A R E G / E R E G$ expression is associated with better outcome in C/P-treated patients with CRC. Khambata-Ford et al. used microarrays to compare the expression of various genes between a disease control group and a non-responders group in a cohort of $80 \mathrm{CRC}$ patients who received CTX monotherapy; $A R E G$ and EREG showed significant differential expression, with the lowest p-values (2). They showed that CTX-treated patients with high EREG- or AREGexpressing tumors have significantly longer PFS than patients with low expression. Jacobs et al. found that EREG and AREG expression was significantly associated with RR, disease control, PFS, and OS in 121 patients with irinotecanrefractory, KRAS wt metastatic CRC who received a combination of CTX and irinotecan (3). Several other reports showed similar results; high AREG and/or EREG expression were related to better response for patients who received $\mathrm{C} / \mathrm{P}$ (4-13). Similarly, our study also showed the patients with high AREG/EREG had better RR and longer OS than those with low levels among CP-treated patients with $K R A S^{w t} \mathrm{CRC}$. These results were reproducible in every reported study, which indicates that $A R E G$ and $E R E G$ could be reliable biomarkers when combined with $R A S / B R A F$ mutation status.
In contrast to these investigations, two studies on first-line treatments failed to show the benefit of AREG and EREG as predictive biomarkers in CRC in patients treated with CTX combined with multiple cytotoxic agents $(9,23)$. Cytotoxic chemotherapy shows promising effect along with biological agents in first-line settings, demonstrating remarkable additional survival benefit with biological agents may be difficult. The CRYSTAL trial, which compared FOLFIRI + CTX vs. FOLFIRI alone in the first-line setting, showed only a 0.9-month median gain in PFS (24), whereas late-line use of biological agents showed longer survival gains with remarkable hazard ratio improvement $(25,26)$. Where our study also showed remarkable OS separation by EREG expression, most of our cohort patients in our study received anti-EGFR agents as second- or third-line treatments. Thus, these reports $(9,23)$ do not show $A R E G$ and $E R E G$ to be equivocal predictive markers for $\mathrm{C} / \mathrm{P}$ response in the firstline setting. Sunakawa et al. showed the effectiveness of $A R E G$ as a predictive biomarker for response to CTX in a first-line setting (11).

Our study showed that EREG was more likely to affect survival time, whereas $A R E G$ was more likely to affect response rate. AREG and EREG are both located in $4 \mathrm{q} 13.3$ chromosome, and their expression levels were strongly 
correlated. We previously reported strong correlations between AREG mRNA expression and EREG mRNA expression $(\mathrm{Rs}=0.82, p<0.0001$, Spearman correlation test) (21). Thus, $A R E G^{\text {High }}$ tumors are also likely to be $E R E G^{\text {High }}$. Oliveras-Ferraros et al. reported that stable silencing of either $A R E G$ or EREG was found to reduce the expression of the other ligand in a squamous cell carcinoma cell line (27). As their expression is strongly correlated, the significance of AREG and EREG as biomarkers might not intrinsically differ.

This study has several limitations. First, this was a retrospective observational study with somewhat diverse patient backgrounds, relatively few patients received $\mathrm{C} / \mathrm{P}$, tissue collection timing varied, and minor $R A S$ and $B R A F$ mutations were not examined. Although many previous studies report $A R E G$ and $E R E G$ to be promising biomarkers for predicting response to $\mathrm{C} / \mathrm{P}$, several problems must be overcome to make them practicable. Most previous studies measured AREG/EREG mRNA expression as biomarkers, either using microarray or real-time RT-PCR. When quantitative PCR is used, relative quantitative values may change under various conditions, such as probe/primer design, length of amplicon, internal reference genes, types of PCR machines and protocols. Standardizing these conditions among various laboratories may be difficult. Optimal cut-off values are also undetermined. For quality control, standardization of methods for RNA extraction, reverse transcription, and PCR conditions are critical for obtaining consistent and reliable gene expression measurement for clinical use.

In conclusion, $A R E G$ and $E R E G$ expression was a reliable predictor of response to $\mathrm{C} / \mathrm{P}$, and was higher in left-sided $\mathrm{CRC}$ than in right-sided CRC. Although these data may help explain why $\mathrm{C} / \mathrm{P}$ is more effective in left-sided tumors than in right-sided tumors, further studies are warranted to elucidate the mechanism of this phenomenon.

\section{Conflicts of Interest}

The Authors declare that there are no conflicts of interest regarding this study.

\section{Author's Contributions}

H.K. and G.N. designed and performed experiments, analyzed the data. H.K. wrote the manuscript. K.H., T.A., and M.Y. organized the study, and reviewed and edited the manuscript.

\section{Acknowledgements}

The Authors thank Mr. Kanta Osuga, Ms. Saki Okamoto, Ms. Mieko Hirokawa, and Ms. Sachie Ishibashi for technical assistance of the experiment. The Authors also thank Mr. Tomotaka Yokochi for statistical advices, and Marla Brunker, from Edanz Group (www.edanzediting.com/ac) for editing a draft of this manuscript.

\section{References}

1 Inatomi $\mathrm{O}$, Andoh $\mathrm{A}$, Yagi $\mathrm{Y}$, Bamba $\mathrm{S}$, Tsujikawa $\mathrm{T}$ and Fujiyama Y: Regulation of amphiregulin and epiregulin expression in human colonic subepithelial myofibroblasts. Int $\mathbf{J}$ Mol Med 18(3): 497-503, 2006. PMID: 16865236.

2 Khambata-Ford S, Garrett CR, Meropol NJ, Basik M, Harbison CT, Wu S, Wong TW, Huang X, Takimoto CH, Godwin AK, Tan BR, Krishnamurthi SS, Burris HA, 3rd, Poplin EA, Hidalgo M, Baselga J, Clark EA and Mauro DJ: Expression of epiregulin and amphiregulin and k-ras mutation status predict disease control in metastatic colorectal cancer patients treated with cetuximab. J Clin Oncol 25(22): 3230-3237, 2007. PMID: 17664471. DOI: $10.1200 /$ JCO.2006.10.5437

3 Jacobs B, De Roock W, Piessevaux H, Van Oirbeek R, Biesmans B, De Schutter J, Fieuws S, Vandesompele J, Peeters M, Van Laethem JL, Humblet Y, Penault-Llorca F, De Hertogh G, Laurent-Puig P, Van Cutsem E and Tejpar S: Amphiregulin and epiregulin mrna expression in primary tumors predicts outcome in metastatic colorectal cancer treated with cetuximab. J Clin Oncol 27(30): 5068-5074, 2009. PMID: 19738126. DOI: 10.1200/JCO.2008.21.3744

4 Baker JB, Dutta D, Watson D, Maddala T, Munneke BM, Shak S, Rowinsky EK, Xu LA, Harbison CT, Clark EA, Mauro DJ and Khambata-Ford S: Tumour gene expression predicts response to cetuximab in patients with kras wild-type metastatic colorectal cancer. Br J Cancer 104(3): 488-495, 2011. PMID: 21206494. DOI: 10.1038/sj.bjc.6606054

5 Jonker DJ, Karapetis CS, Harbison C, O'Callaghan CJ, Tu D, Simes RJ, Malone DP, Langer C, Tebbutt N, Price TJ, Shapiro J, Siu LL, Wong RP, Bjarnason G, Moore MJ, Zalcberg JR and Khambata-Ford S: Epiregulin gene expression as a biomarker of benefit from cetuximab in the treatment of advanced colorectal cancer. Br J Cancer 110(3): 648-655, 2014. PMID: 24335920. DOI: $10.1038 / \mathrm{bjc} .2013 .753$.

6 Seligmann JF, Elliott F, Richman SD, Jacobs B, Hemmings G, Brown S, Barrett JH, Tejpar S, Quirke P and Seymour MT: Combined epiregulin and amphiregulin expression levels as a predictive biomarker for panitumumab therapy benefit or lack of benefit in patients with ras wild-type advanced colorectal cancer. JAMA Oncol, 2016. PMID: 26867820. DOI: 10.1001/ jamaoncol.2015.6065

7 Pentheroudakis G, Kotoula V, De Roock W, Kouvatseas G, Papakostas P, Makatsoris T, Papamichael D, Xanthakis I, Sgouros J, Televantou D, Kafiri G, Tsamandas AC, Razis E, Galani E, Bafaloukos D, Efstratiou I, Bompolaki I, Pectasides D, Pavlidis N, Tejpar S and Fountzilas G: Biomarkers of benefit from cetuximab-based therapy in metastatic colorectal cancer: Interaction of egfr ligand expression with ras/raf, pik3ca genotypes. BMC Cancer 13: 49, 2013. PMID: 23374602. DOI: 10.1186/1471-2407-13-49

8 Saridaki Z, Tzardi M, Papadaki C, Sfakianaki M, Pega F, Kalikaki A, Tsakalaki E, Trypaki M, Messaritakis I, Stathopoulos E, Mavroudis D, Georgoulias V and Souglakos J: Impact of kras, braf, pik3ca mutations, pten, areg, ereg expression and skin rash in $>/=2$ line cetuximab-based therapy of colorectal cancer patients. PLoS One 6(1): e15980, 2011. PMID: 21283802. DOI: 10.1371/journal.pone.0015980

9 Cushman SM, Jiang C, Hatch AJ, Shterev I, Sibley AB, Niedzwiecki D, Venook AP, Owzar K, Hurwitz HI and Nixon 
$\mathrm{AB}$ : Gene expression markers of efficacy and resistance to cetuximab treatment in metastatic colorectal cancer: Results from calgb 80203 (alliance). Clin Cancer Res 21(5): 1078-1086, 2015. PMID: 25520391. DOI: 10.1158/1078-0432.CCR-14-2313

10 Llovet P, Sastre J, Ortega JS, Bando I, Ferrer M, Garcia-Alfonso P, Donnay O, Carrato A, Jimenez A, Aranda E, Leon A, Gravalos C, Camara JC, Feliu J, Sanchiz B, Caldes T and Diaz-Rubio E: Prognostic value of braf, pi3k, pten, egfr copy number, amphiregulin and epiregulin status in patients with kras codon 12 wild-type metastatic colorectal cancer receiving first-line chemotherapy with anti-egfr therapy. Mol Diagn Ther 19(6): 397408, 2015. PMID: 26341080. DOI: 10.1007/s40291-015-0165-0

11 Sunakawa Y, Yang D, Moran M, Astrow SH, Tsuji A, Stephens C, Zhang W, Cao S, Takahashi T, Denda T, Shimada K, Kochi M, Nakamura M, Kotaka M, Segawa Y, Masuishi T, Takeuchi M, Fujii M, Nakajima T, Ichikawa W and Lenz HJ: Combined assessment of egfr-related molecules to predict outcome of 1stline cetuximab-containing chemotherapy for metastatic colorectal cancer. Cancer Biol Ther 17(7): 751-759, 2016. PMID: 27104867. DOI: 10.1080/15384047.2016.1178426

12 Jing C, Jin YH, You Z, Qiong Q and Jun Z: Prognostic value of amphiregulin and epiregulin mrna expression in metastatic colorectal cancer patients. Oncotarget 7(34): 55890-55899, 2016. PMID: 27344184. DOI: 10.18632/oncotarget.10151

13 Seligmann JF, Hatch AJ, Richman SD, Elliott F, Jacobs B, Brown S, Hurwitz H, Barrett JH, Quirke P, Nixon AB and Seymour MT: Association of tumor her3 messenger rna expression with panitumumab efficacy in advanced colorectal cancer. JAMA Oncol 4(4): 564-568, 2018. PMID: 29075780. DOI: $10.1001 /$ jamaoncol.2017.3168

14 Schrag D, Weng S, Brooks G, Meyerhardt JA and Venook AP: The relationship between primary tumor sidedness and prognosis in colorectal cancer. Journal of Clinical Oncology 34(15_suppl): 3505-3505, 2016.

15 Venook AP, Ou F-S, Lenz H-J, Kabbarah O, Qu X, Niedzwiecki D, Zemla T, Goldberg RM, Hochster HS, O’Neil BH, Sanoff HK, Mayer RJ, Bertagnolli MM, Blanke CD and Innocenti F: Primary $\left(1^{\circ}\right)$ tumor location as an independent prognostic marker from molecular features for overall survival (os) in patients (pts) with metastatic colorectal cancer (mcrc): Analysis of calgb/ swog 80405 (alliance). Journal of Clinical Oncology 35(15_suppl): 3503-3503, 2017.

16 Arnold D, Lueza B, Douillard JY, Peeters M, Lenz HJ, Venook A, Heinemann V, Van Cutsem E, Pignon JP, Tabernero J, Cervantes A and Ciardiello F: Prognostic and predictive value of primary tumour side in patients with ras wild-type metastatic colorectal cancer treated with chemotherapy and egfr directed antibodies in six randomized trials. Ann Oncol 28(8): 17131729, 2017. PMID: 28407110. DOI: $10.1093 /$ annonc/mdx 175

17 Boeckx N, Koukakis R, Op de Beeck K, Rolfo C, Van Camp G, Siena S, Tabernero J, Douillard JY, Andre T and Peeters M: Primary tumor sidedness has an impact on prognosis and treatment outcome in metastatic colorectal cancer: Results from two randomized first-line panitumumab studies. Ann Oncol 28(8): 1862-1868, 2017. PMID: 28449055. DOI: 10.1200/JCO. 2008.21.3744

18 Brule SY, Jonker DJ, Karapetis CS, O'Callaghan CJ, Moore MJ, Wong R, Tebbutt NC, Underhill C, Yip D, Zalcberg JR, Tu D and Goodwin RA: Location of colon cancer (right-sided versus left-sided) as a prognostic factor and a predictor of benefit from cetuximab in ncic co.17. Eur J Cancer 51(11): 1405-1414, 2015. PMID: 25979833. DOI: 10.1016/j.ejca.2015.03.015

19 Tejpar S, Stintzing S, Ciardiello F, Tabernero J, Van Cutsem E, Beier F, Esser R, Lenz HJ and Heinemann V: Prognostic and predictive relevance of primary tumor location in patients with ras wild-type metastatic colorectal cancer: Retrospective analyses of the crystal and fire-3 trials. JAMA Oncol, 2016. PMID: 27722750. DOI: 10.1001/jamaoncol.2016.3797

20 Lee MS, McGuffey EJ, Morris JS, Manyam G, Baladandayuthapani V, Wei W, Morris VK, Overman MJ, Maru DM, Jiang ZQ, Hamilton SR and Kopetz S: Association of cpg island methylator phenotype and ereg/areg methylation and expression in colorectal cancer. Br J Cancer 114(12): 1352-1361, 2016. PMID: 27272216. DOI: $10.1038 / b j c .2016 .87$

21 Kuramochi H, Nakajima G, Kaneko Y, Nakamura A, Inoue Y, Yamamoto $\mathrm{M}$ and Hayashi K: Amphiregulin and epiregulin mrna expression in primary colorectal cancer and corresponding liver metastases. BMC Cancer 12: 88, 2012. PMID: 22409860. DOI: 10.1186/1471-2407-12-88

22 Kaneko Y, Kuramochi H, Nakajima G, Inoue Y and Yamamoto M: Degraded DNA may induce discordance of kras status between primary colorectal cancer and corresponding liver metastases. Int J Clin Oncol 19(1): 113-120, 2014. PMID: 23299277. DOI: 10.1007/s10147-012-0507-4

23 Adams RA, Fisher D, Farragher S, Jasani B, Smith CG, James MD, Cheadle J, Nichols LL, Meade AM, Kaplan RS, Wilson RH, Wasan H and Maughan T: Use of epiregulin (ereg) and amphiregulin (areg) gene expression to predict response to cetuximab (cet) in combination with oxaliplatin (ox) and $5 \mathrm{fu}$ in the first-line treatment of advanced colorectal cancer (acrc). Journal of Clinical Oncology 30(30_suppl): 32-32, 2012.

24 Van Cutsem E, Kohne CH, Hitre E, Zaluski J, Chang Chien CR, Makhson A, D’Haens G, Pinter T, Lim R, Bodoky G, Roh JK, Folprecht G, Ruff P, Stroh C, Tejpar S, Schlichting M, Nippgen $\mathrm{J}$ and Rougier P: Cetuximab and chemotherapy as initial treatment for metastatic colorectal cancer. N Engl J Med 360(14): 1408-1417, 2009. PMID: 19339720. DOI: 10.1056/ NEJMoa0805019.

25 Jonker DJ, O'Callaghan CJ, Karapetis CS, Zalcberg JR, Tu D, Au HJ, Berry SR, Krahn M, Price T, Simes RJ, Tebbutt NC, van Hazel G, Wierzbicki R, Langer C and Moore MJ: Cetuximab for the treatment of colorectal cancer. N Engl J Med 357(20): 20402048, 2007. PMID: 18003960. DOI: 10.1056/NEJMoa071834

26 Cunningham D, Humblet Y, Siena S, Khayat D, Bleiberg H, Santoro A, Bets D, Mueser M, Harstrick A, Verslype C, Chau I and Van Cutsem E: Cetuximab monotherapy and cetuximab plus irinotecan in irinotecan-refractory metastatic colorectal cancer. N Engl J Med 351(4): 337-345, 2004. PMID: 15269313. DOI: 10.1056/NEJMoa033025

27 Oliveras-Ferraros C, Cufi S, Queralt B, Vazquez-Martin A, Martin-Castillo B, de Llorens R, Bosch-Barrera J, Brunet J and Menendez JA: Cross-suppression of egfr ligands amphiregulin and epiregulin and de-repression of fgfr 3 signalling contribute to cetuximab resistance in wild-type kras tumour cells. Br J Cancer 106(8): 1406-1414, 2012. PMID: 22491422. DOI: $10.1038 /$ bjc. 2012.103

Received July 31, 2019

Revised August 15, 2019

Accepted August 16, 2019 